\title{
SPECIFIC MODELS OF REPRESENTING THE INTELLECTUAL CAPITAL
}

\author{
Andreea Feraru \\ "Vasile Alecsandri" University of Bacau \\ andreea_feraru26@yahool.com \\ Nicoleta Ciucescu \\ "Vasile Alecsandri” University of Bacau \\ ciucnico@yahool.com
}

\begin{abstract}
Various scientists in the modern age of management have launched different models for evaluating intellectual capital, and some of these models are analysed critically in this study, too. Most authors examine intellectual capital from a static perspective and focus on the development of its various evaluation models. In this chapter we surveyed the classical static models: Sveiby, Edvisson, Balanced Scorecard, as well as the canonical model of intellectual capital. In a spectral dynamic analysis, organisational intellectual capital is structured in: organisational knowledge, organisational intelligence, organisational values, and their value is built on certain mechanisms entitled integrators, whose chief constitutive elements are: individual knowledge, individual intelligence and individual cultural values. The organizations, as employers, must especially reconsider those employees' work who value knowledge because they are free to choose how, and especially where they are inclined to invest their own energy, skills and time, and they can be treated as freelancers or as some little entrepreneurs .
\end{abstract}

\section{Keywords}

cognitive knowledge; emotional knowledge; spiritual knowledge; human capital; structural capital and relational capital

\section{JEL Classification}

F15; F50; O10

\section{Statistical Models of Representing Intellectual Capital}

The chapter entitled Statistical Models of Representing Intellectual Capital approaches and analyses the concept of intellectual capital, as well as the main models which can support enterprisers/managers in evaluating and quantifying the advantages of intellectual capital. Most authors examine intellectual capital from a static perspective and focus on the development of its various evaluation models. In this chapter we surveyed the classical static models: Sveiby, Edvisson, Balanced Scorecard, as well as the canonical model of intellectual capital.

Among the group of static models for evaluating organisational intellectual capital the canonical model stands out.

This model enables the structuring of organisational intellectual capital in: human capital, structural capital and relational capital. Although the model is widely spread, it is a static one and can thus create a series of errors in the process of evaluation, because all the three entities mentioned above are not independent from the viewpoint of their contents, as any logic of structuring complex entities requires.

The human capital is the component that integrates the intellectual capital resources associated to the intangible human resources inside an organization. The formal definition of the human capital can be found in the Dictionary of Economics, rendered 
as, "the stock of professional knowledge, skills, abilities and health that can determine a person to enhance its creative capabilities, and, thus, the expected future revenues; it means, also, the ability to get people to the effective production of the goods and services".

As proved by the almost comprehensive analysis carried out by Andriessen (2004) and, more recently, by Roos and Pike (2007), most authors interpret intellectual capital as organisational potential structured in the following manner: human capital, structural capital and relational capital. No matter what designations they might use, static models approach the manifestation of organizational intellectual capital after its foundation (Stewart, 1999; Roos et al., 1997; Sveiby, 1997; Andriessen, 2004).

In turn, the human capital can be divided into individual capital, which includes knowledge, skills, personal skills and the social capital, aiming the human relationships at the workplaces. Several studies show that in the U.S. companies, the value of human capital exceeds the capital structure and the value of the relational capital.

That is why all this research has a static character, examining a taxonomy reflecting a type of fixed reality, and not one which is dynamic and changing. In the context of a continuously changing and evolving economy, the most important resource for any enterprise is its human capital. However, the simple existence of a number of employees is not sufficient for making the difference in value between one organisation and another; what represents and constitutes its competitive advantage is the quality of its personnel, their competences, abilities, knowledge and their performance- and success-oriented views.

Could we say that the implication of performance-oriented employees and the existence of a work environment which stimulates creativity and innovation are enough for long-term business success? Certainly, this is not enough because an organisation does not operate by itself, it functions in a certain context and establishes relations with various actors of the organisational environment (stakeholders, clients, suppliers, shareholders, state institutions etc.). That is why the relational component of intellectual capital is as important as its human and structural components. An organisation must concentrate its financial and human efforts on building and maintaining long-term relationships with all its business partners, with the target market and with the society in general.

Leif Edvinsson, in line with the scheme of market value, divides intellectual capital in human capital and structural capital which, in its turn, is formed of client capital and organisational capital, the latter comprising innovation capital and process capital. Although this classification seems to be well-structured, it makes use of groups of entities which are not defined rigorously and do not possess unique features.

Sveiby's model divides intangible assets in external structure, internal structure and individual competences. As far as the external structure is concerned, we must mention that it refers to clients, suppliers and other stakeholders who are considered relevant for a certain company. Depending on the type of organisation, the external structure will differ from one enterprise to another. The internal structure refers to systems, databases and processes which support the organisation, whereas individual competences concern the employees' individual experience, knowledge, competences, abilities and ideas.

The model developed by Norton and Kaplan does not present intellectual capital from the perspective of its components. The Balanced Scorecard model analyses an organisation from four perspectives: that of learning and development/growth, internal processes perspective, clients' perspective and financial perspective, a model which largely resembles some of the classifications of intellectual capital centred on components which were exposed above. 
After carefully investigating the bibliographical support, we selected and analysed critically all these models. Proper knowledge of these models for evaluating intellectual capital is useful because in the second part of the research we tested a new model for evaluating intellectual capital.

\section{Dynamic Models for Representing Intellectual Capital}

The chapter entitled Dynamic Models for Representing Intellectual Capital presents the main models regarding the dynamics of knowledge developed through time. In concrete terms, it contains the approach of intellectual capital from the perspective of organisational integrators, the clarification of concepts like linearity and non-linearity for analysing organisational knowledge fields, or knowledge processing, as well as the presentation of the entropic model of intellectual capital (Brătianu et al, 2009).

Given the importance and dynamics integrators within an organization, has been prepared and developed a model of intellectual capital as follows:

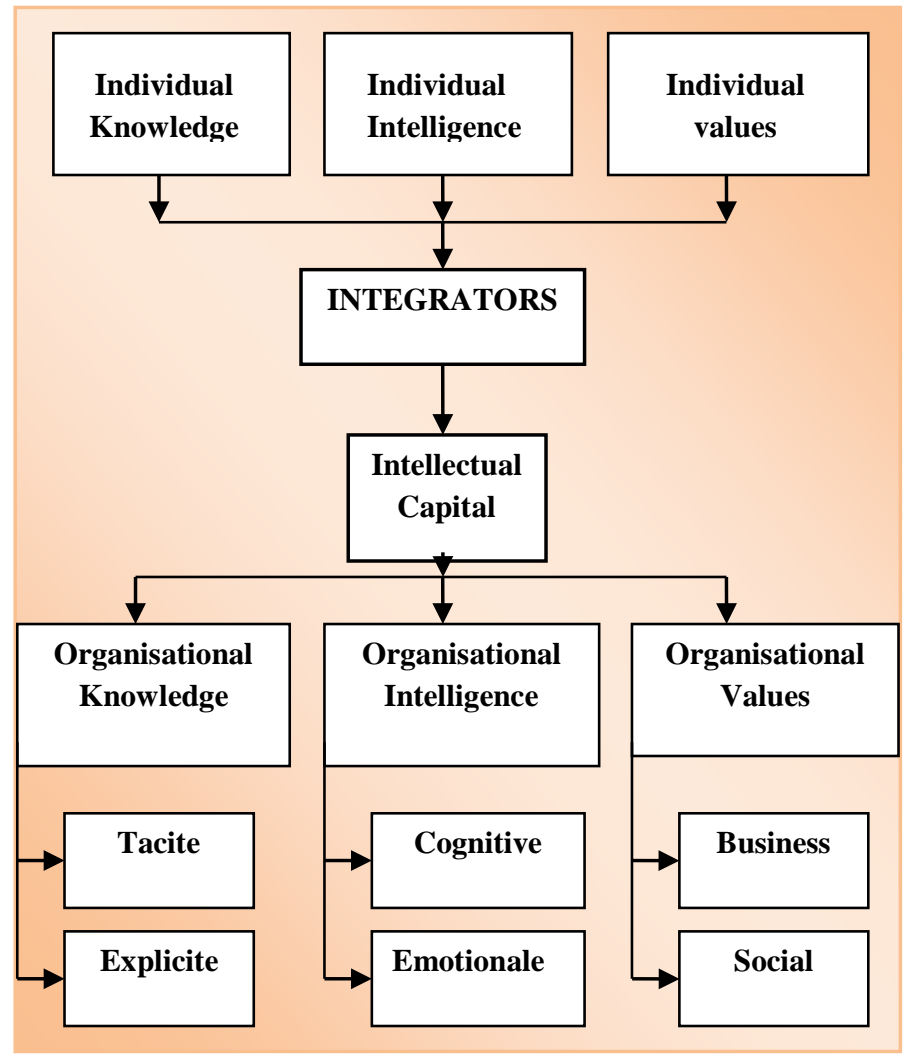

Figure 1 The integrated perspective on intellectual capital Source: Brătianu C., 2009, p. 235

In a spectral dynamic analysis, organisational intellectual capital is structured in: organisational knowledge, organisational intelligence, organisational values, and their value is built on certain mechanisms entitled integrators, whose chief constitutive elements are: individual knowledge, individual intelligence and individual cultural values.

The following elements can be part of the general designation of organisational knowledge: values, beliefs, rituals within the organisation, organisational culture, 
knowledge stored in existing software, licenses, patents, or in organisational databases.

Other elements are added to these, such as the tacit and explicit knowledge of the organisation members, knowledge which is used in daily activities and processes. According to a simple analysis, we could affirm that organisational knowledge includes tacit and explicit knowledge, but this knowledge dyad is replaced with a new perspective: that of cognitive knowledge, emotional knowledge and spiritual knowledge.

In order to understand this new manner of approaching knowledge, we will make a brief presentation of this perspective. Specialists in Eastern Europe replaced the Cartesian mind-body duality with a unitary conception regarding knowledge; this means that both cognitive and emotional knowledge can change continuously from one form to another by virtue of the thermodynamics metaphor. While Western philosophy excluded affectivity from the class of knowledge because of its subjective nature, Eastern philosophy extended the scope of knowledge to include affectivity as well, and this is an important element for leadership because employees are motivated especially by means of emotional knowledge. At the same time, innovation is based on intuition, which has both a cognitive and an emotional character.

Cognitive knowledge is regarded as the direct result of the cognitive process, since they comprise the rational part of the cognitive process. Cognitive knowledge contains both rational and non-rational knowledge, so it would be a mistake to consider the spectrum of cognitive knowledge only from the perspective of rational characteristics.

Emotional knowledge is based on emotions which occur before cognitive processes and they influence the way in which we process information. Emotional knowledge shows resemblance both in contents and intensity with the two dimensions of thermodynamic energy.

Spiritual knowledge contains the most profound significations, values, objectives and the highest motivations, both at individual and organisational levels. Spiritual knowledge is held in common by all employees and they generate the necessary motivations for their efforts to accomplish a durable competitive advantage. The vision and mission of an enterprise are strongly supported by corporate values, which are integrated in the field of spiritual knowledge. Each employee enters an organisation possessing his/her own collection of cognitive, spiritual and affective knowledge.

These types of individual knowledge can be shared, transferred or employed directly in the decision-making process, resulting from the action of organisational integrators. One of the most important problems for each organisation is that of integrating employees' individual knowledge and intelligence so as to create organisational knowledge and intelligence. In order to achieve this aim, an organisation needs some specific mechanisms for the generation of synergies.

This fact is true because in non-linear systems, as in the case of knowledge, the outcome means more than the simple addition of individual achievements. Each type of knowledge can be processed by a specific kind of intelligence, so that we obtain a final result for the entire organisation, namely the organisational intellectual capital. Organisational intelligence - a component of the intellectual capital possessed by each member of the enterprise - has an important contribution to organisational intellectual capital. The processing of knowledge is performed with the help of intelligence and decisions taken make use of the values of organisational culture as guiding factors. Organisational values are composed, in their turn, of cultural values and business values.

Unlike previously mentioned models, the entropic model reveals the dynamic transformation of potential intellectual capital in usable intellectual capital, just like 
energetic models in physics reflect the transformation of the potential energy of a body or a mechanical system into kinetic exploitable energy. First, the individual contribution of each employee, existing under the form of knowledge, ways of thinking, emotions, behaviour patterns and values, is transformed into organisational capital with the support of integrators.

This chapter aims to demonstrate the fact that we can change the viewpoint of perceiving and approaching intellectual capital, so that its generation could be analysed and improved.

In fact, by positioning the intellectual capital in the centre, we can observe the roots rather than look up and examine the branches. Thus, we can argue that the value of intellectual capital depends on certain organisational mechanisms, hereafter named integrators. By introducing the concept of integrator (Brătianu, 2008), new options were revealed for researching the dynamics of intellectual capital in an organisation, as well as the practical methods for its development as a potentiating factor or, respectively, for its transfer in managerial action.

An integrator represents a tangible or intangible system for aggregating individual contributions on the basis of a non-linear regulation. Hence, it does not refer to the summing up of individual contributions, but to their integration. The ultimate outcome does not reflect a value resulting from the multiplication of the number of employees, but signifies a value which is greater or smaller than the multiplication of individual intellectual capital.

In a subsequent stage, the differentiation of organisational intellectual capital occurs, in order to meet the clients' demands and requirements to the best possible degree. These integrators are detailed and analysed from the perspective of developing the intellectual capital. They are capable of bringing together primary constituents and of integrating them in the intellectual capital of the entire organisation, with the aid of synergy, similar to the process of projecting a system.

\section{Conclusion}

Additionally, while analysing the entropic model, we also investigated the influence of major integrators on intellectual capital, with its three components: cognitive capital, emotional capital, spiritual capital, as well as the field of factors which exerts force on the primary components of intellectual capital - knowledge, intelligence and values - and determines the generation and development of intellectual capital.

The management and the leadership are a powerful integrator in the nonlinear segment. The leadership is important by its power to act on knowledge, on the intelligence and on the individual values.

The organizational vision and mission are also interesting integrators, which act mainly on the individual emotional intelligence. The organizational culture appears as a powerful integrator, since it acts mainly on the individual intelligence and on the values, creating models of the organizational behavior.

Intellectual capital as a dynamic approach focuses on the development of entropic model - which captures the dynamic transformation of intellectual capital into usable intellectual capital.

Also, was analyzed the influence of the main integrators intellectual capital, divided into three components: cognitive capital, emotional capital, spiritual capital, and fields of forces acting on the primary constituent of intellectual capital - knowledge, intelligence and values - and determines the generation and development of intellectual capital. 


\section{References}

Andriessen, D. (2004), Making Sense of Intellectual Capital - Designing a Method for the Valuation of Intangibles, Butterworth-Heineman, Burlington (MA) and Oxford (UK).

Brătianu, C., (2008a), Knowledge dynamics, Review of Management and Economic Engineering, Vol.7, Special Issue, No.5, pp.103-107.

Brătianu, C., (2008b), A dynamic structure of the organizational intellectual capital, in: Naaranoja, M. (ed.) Knowledge management in organizations, pp.233-243. Vaasa: Vaasan Yliopisto.

Brătianu, C. (2009) The frontier of linearity in the intellectual capital metaphor, Electronic Journal of Knowledge Management, vol. 7, issue 4.

Brătianu, C., Vasilache, S., Mandruleanu, A., Dumitru, I., Prejmerean, M., Amza, D. (2009), Capitalul intelectual organizațional. București : Editura ASE București.

Brătianu, C., Dima, A.M., Vasilache, S., Orzea, I. (2012) Nonlinear integrators and intellectual capital dynamics. București : Editura Curtea Veche.

Brătianu, C. (2013) Nonlinear integrators of the organizational intellectual capital. In M. Fathi (Ed.) Integration of practice - oriented knowledge technology: trends and perspectives, pp.3-16, Springer, New York.

Brătianu, C., Orzea, I. (2013) The entropic intellectual capital mode, Knowledge Management Research \& Practice, 11(2), pp.133-141.

Gardner, H. (2006) Multiple intelligences, New Horizons, New York.

Davenport, T.H. si Prusak, L. (2000), Working Knowledge, Harvard Business School Press, Boston.

Gardner, H. (2006), Multiple intelligences, New Horizons, New York.

Feraru, A., Mironescu R. (2012), The intellectual capital and the learning organization, Journal of International Scientific Publication, Economy \& Business, Bulgaria, ISSN 1313-2555, vol. 6., partea a 3-a, pp. 30-40.

Feraru, A., Mironescu R. (2012), E.U.'s Strategy of Building a Knowledge Economy, Studies and Scientific Researches Edition Economics, ISSN 2066-561X, nr.1617, pp. 147-152

Feraru, A., Mironescu R.şi Drob C. (2013), Particular Aspects In Intellectual Capital Management of the Romanian SMEs, Proceedings European Conference on Intellectual Capital University of the Basque Country, Bilbao, Spain, E-Book ISBN: 978-1-909507-15-9, E-Book ISSN: 2049-0941, Book version ISBN: 978-1-909507-13-5, Book Version ISSN: 2049-0933.

Stewart, T. (1998), Intellectual Capital- The New Wealth of Organizations, London, Nicholas Brealey Publishing House.

Sveiby, K.E. (1997), The intangible assets monitor, Journal of Human Resource Costing and Accounting, Volume 2, Issue 1, pp. 73-97. 